\title{
التعليم الرقهي في ظل التحديات المعاصرة
}

\author{
(إعداد \\ د/ مغراني سليم \\ جامعة خميس مليانة، الجزائر

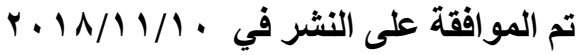 \\ د الجوزي خليفاتي وهيبة \\ جامعة تيزي وزو، الجزائر

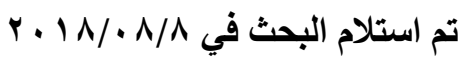

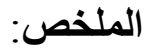

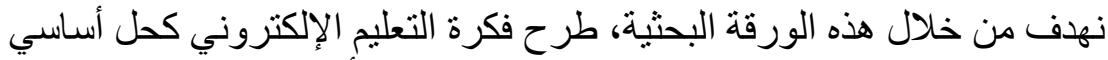

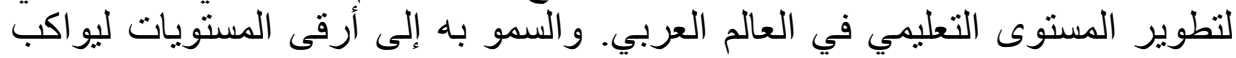

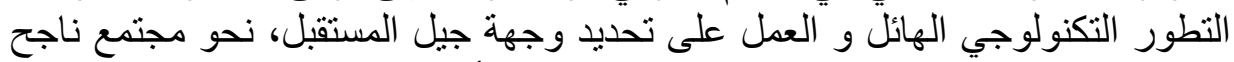

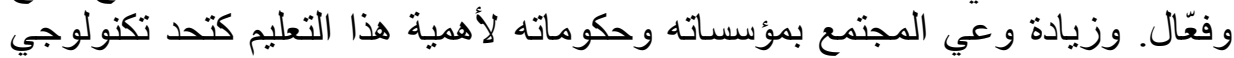

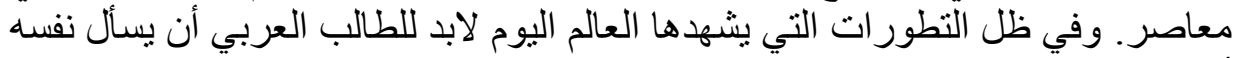

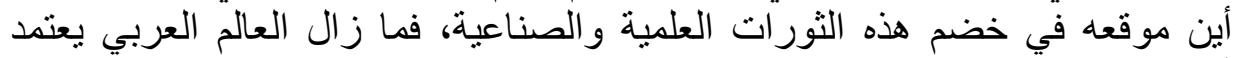

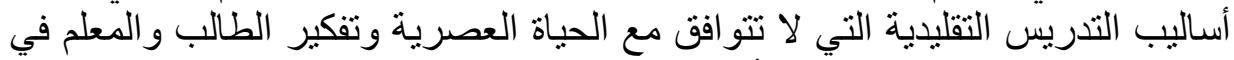

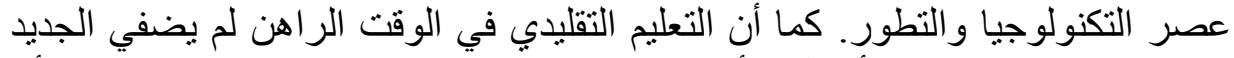

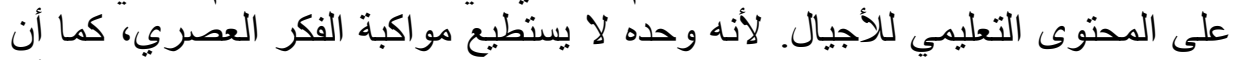

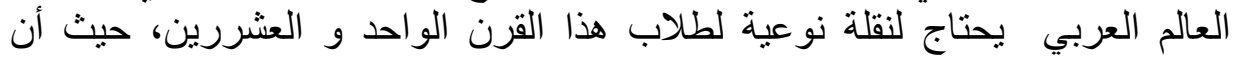

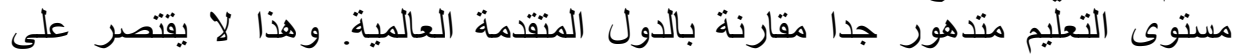

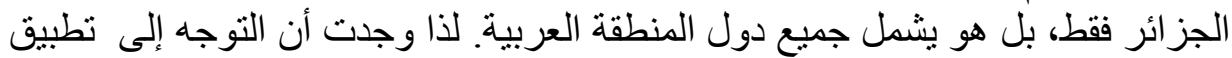

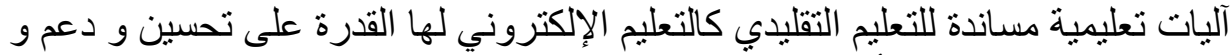

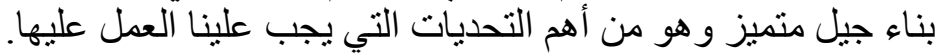

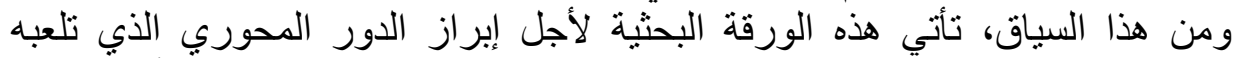

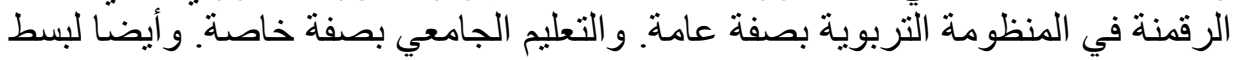
التحديات التي تواجهها المنظومة الرقمية في قطاع التعليم.

\section{Abstract:}

In this paper, we aim to introduce e-learning as a fundamental solution to the development of the educational level in the Arab world. And his Highness to the highest levels to keep abreast of the huge technological development and work to determine the destination of the future generation, towards a successful and effective society. And increase the awareness of the society and its institutions and governments of the importance of this education 


\section{د/وهيية الجوزي ظليفاتي و د/سليم مغراني}

as a contemporary technological challenge. In light of developments in the world today, the Arab student must ask himself where his position in the midst of these scientific and industrial revolutions, the Arab world still adopts traditional teaching methods that are incompatible with modern life and the thinking of the student and teacher in the era of technology and development. Traditional education at the moment does not add new educational content to generations. Because it alone can not keep pace with contemporary thought, and the Arab world needs a qualitative leap for the students of this century and twenty, as the level of education is very low compared to the developed world. This is not limited to Algeria alone, but includes all the countries of the Arab region. Therefore, I found that the approach to the implementation of educational mechanisms in support of traditional education such as e-learning has the ability to improve and support and build a distinct generation, which is one of the most important challenges that we must work on.

It is in this context that this paper comes to highlight the pivotal role played by digitization in the educational system in general. And university education in particular. As well as to spread the challenges faced by the digital system in the education sector.

إنّ ارتفاع مستوى اهتمام الأفراد و المجتمعات بالتكنولوجيا الحديثة في حياتهم

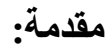

اليومية حدث نتيجة نزايد حركية مجمل حاجاتهم و رغباتهم و انشغالاتهم، و هذا ما افرز

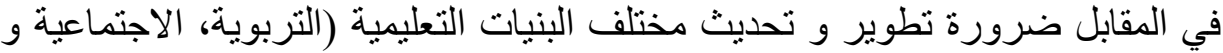

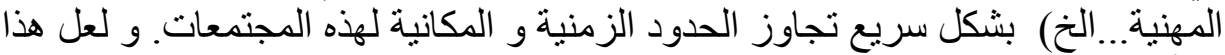
ما أفرز وضع جديد تطلب إلزامية خلق توازي مستمر بين عملية التعلم و تلك البنيات المتطورة التي يجب أن تكون مرنة، ذات قابلية و تفاعل لمو اجهة تحدبات العالم الرقمي.

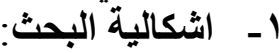

إن التطور التكنولوجي الحاصل اليوم، ادخل قفزة نوعية ايجابية كبيرة في بيئة العملية التعليمية بمختلف أنواعها، و ساعد على إيصال المعلومات و البيانات: العلمية، التربوية و حتى السلوكية للفرد المتعلم (التلميذ، العامل...) الأمر الذي أدى ألى اعلى بدوره إلى تحقيق مجمو عة من الأهداف المسطرة. و ذلك من خلال اعتماد أسلوب التعلم الرقمي أو الالكتروني الذي يعتبر من بين نتائج هذا التطور التكنولوجي و الذي أصنيح

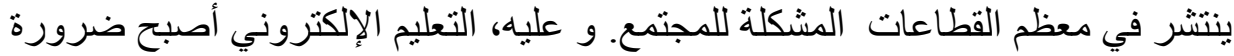
بل وحتمية لمسايرة ركب التطور التكنولوجي الذي شمل كل القطاعات الحيوية في المجتمع. لذلك علينا التمعن في الوضع الراهن اهن للمنظومة التعليمية. ولماذا نحتاج إلى هذا التغيير؟. إذن، لنلقي نظرة على الحلقة التي تتكرر عبر الأجيال والتي تتمثل بالمر احل 
المرحلة الأولى: التعليم المدرسي الذي يقوده المعلمون. والمرحلة الثانية: الجامعي الذي كئي

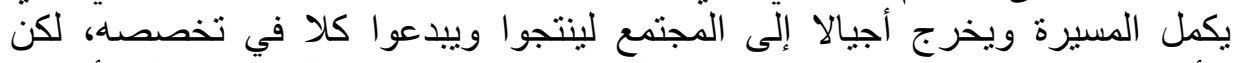

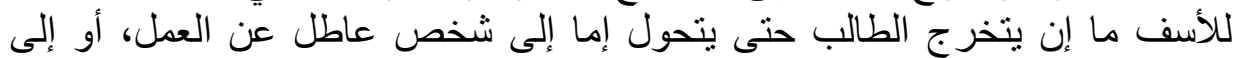

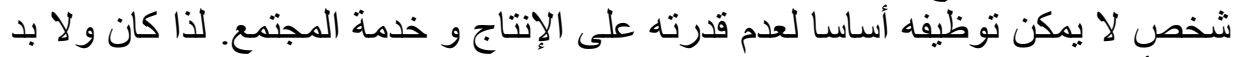

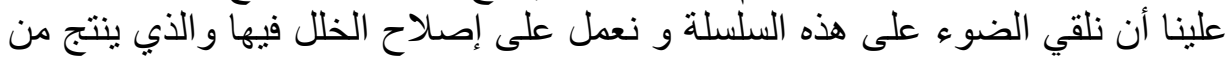

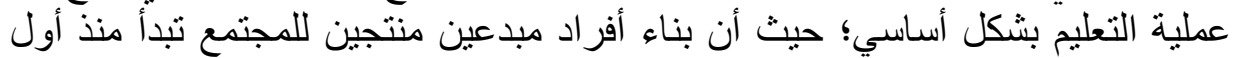

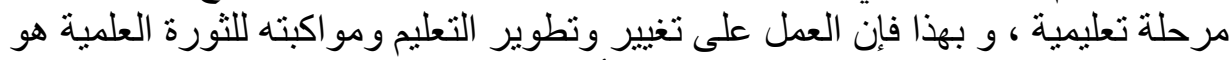

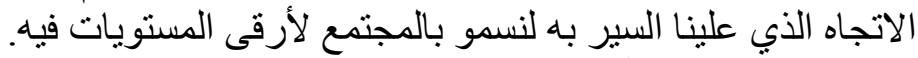

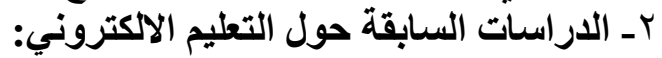

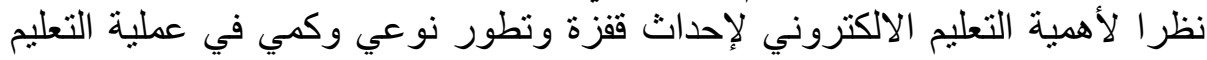

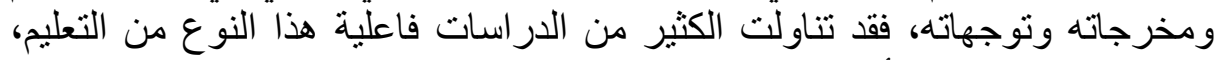

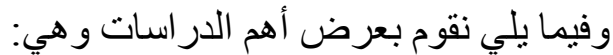

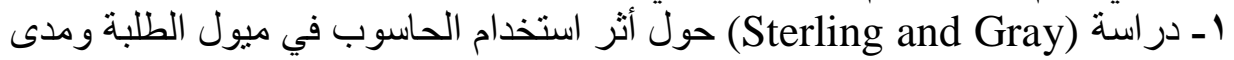

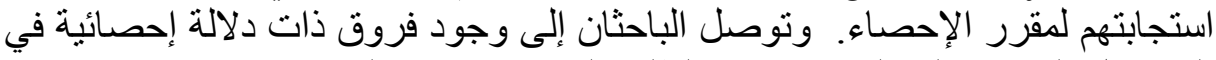

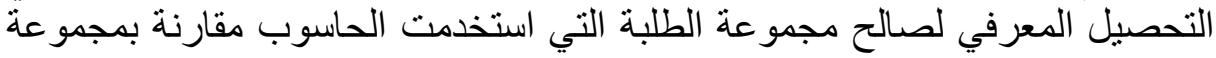
Sterling,J,Gray,M, (1991) (4), pp 51- الطلبة التي درست بالطريقة التقليدية.

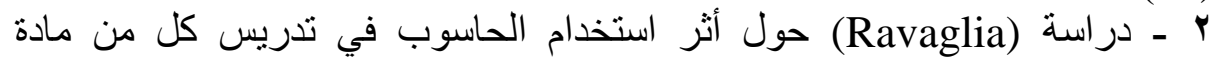

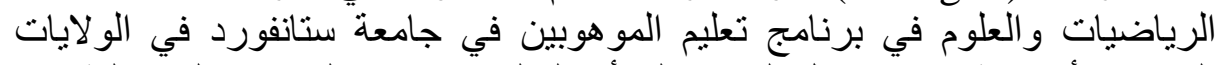

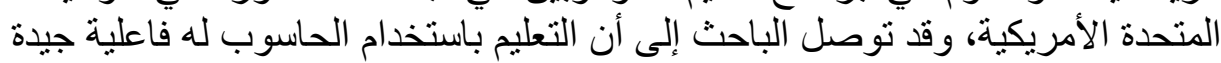

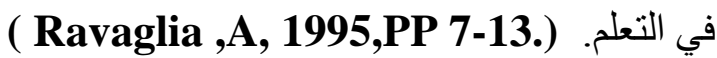
r- در اسة (Watkins) حول استقصاء فعالية التدريس باستخدام برمجية الوسائط

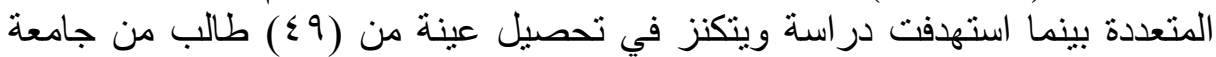

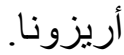

و اتجاهاتهم نحو العلوم، المخزنة على قرص مدمج CD وقد استخدمت هذه

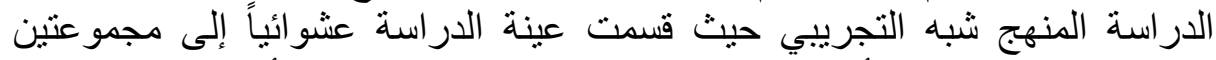

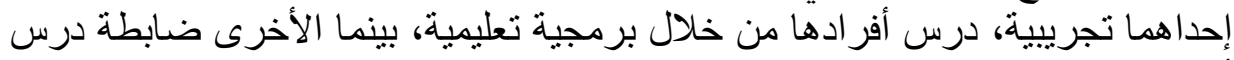

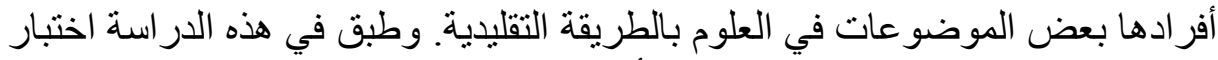

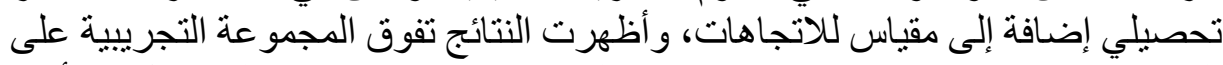

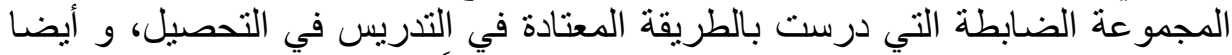

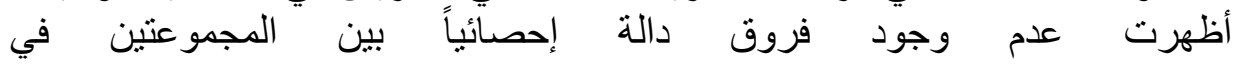
الاتجاهات (Watkins,G,1999,D.A.I.571(5),october,A). 


\section{د/وهيية الجوزي ظليفاتي و د/سليم مغراني}

و بالنظر لما يحمله التعليم الالكتروني من مزايا، فقد بادرت عدد من الدول

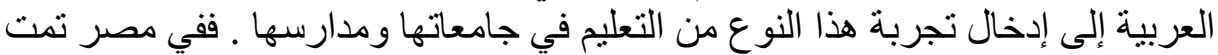

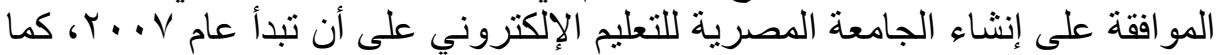

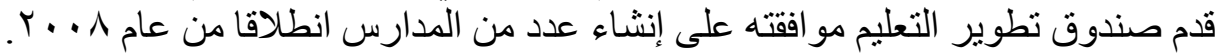

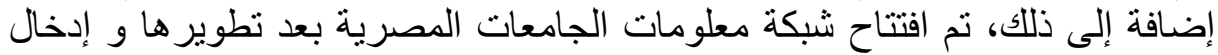

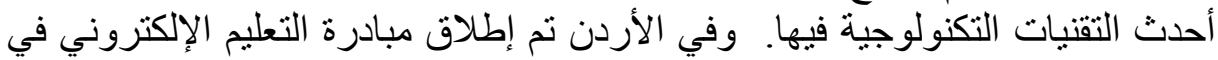

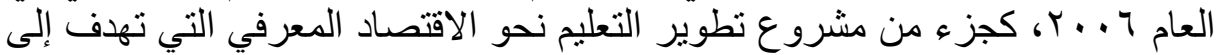

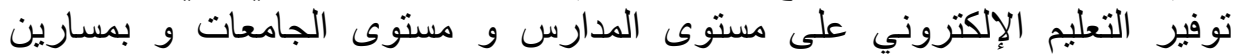

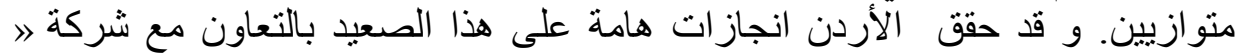

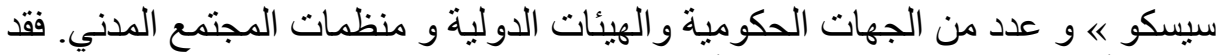

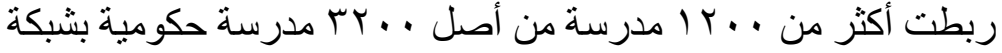

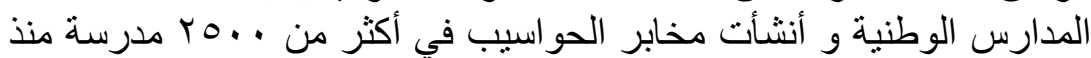

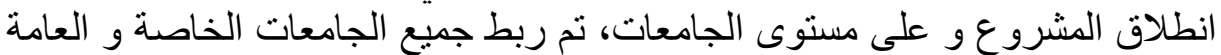

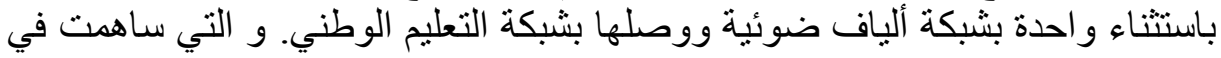

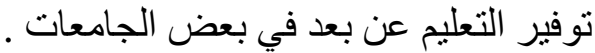

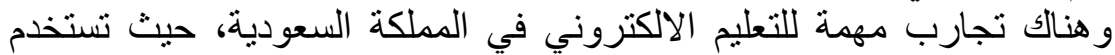

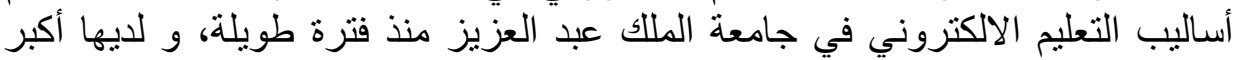

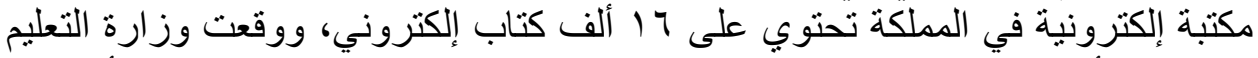

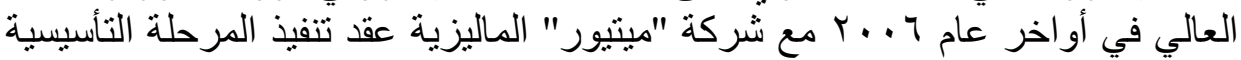

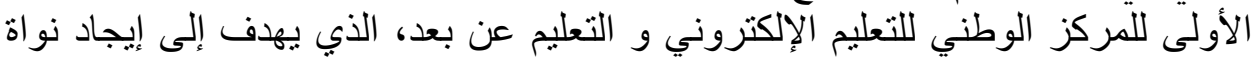

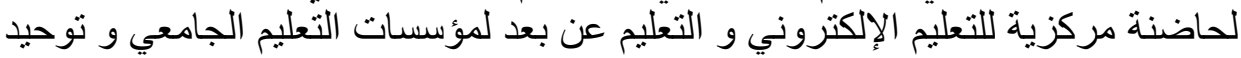

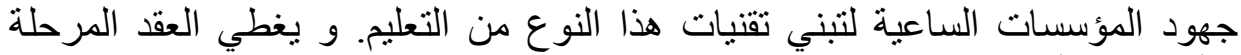

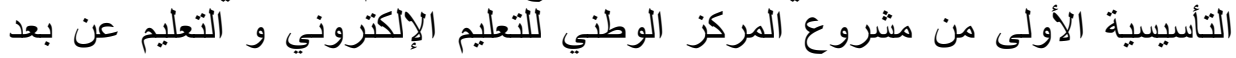

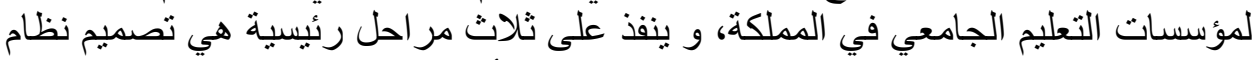

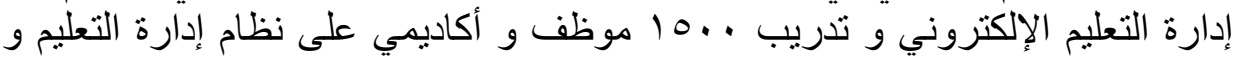

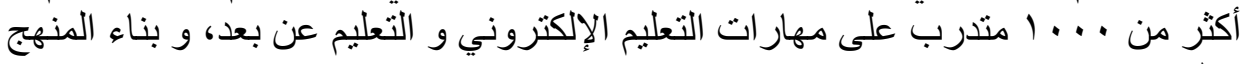

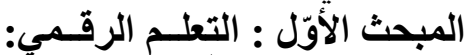

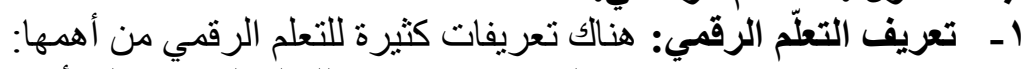

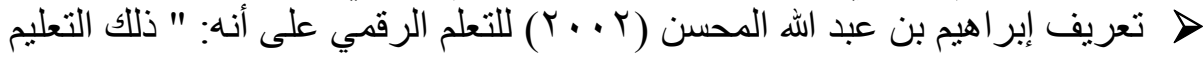

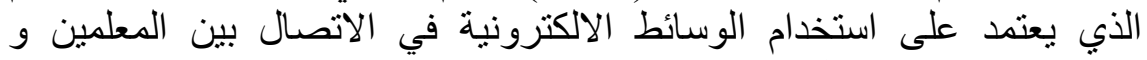

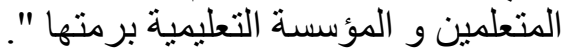




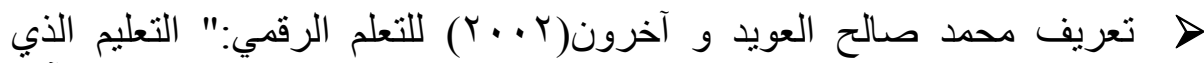

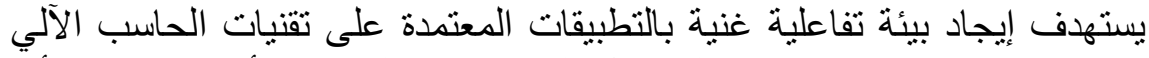

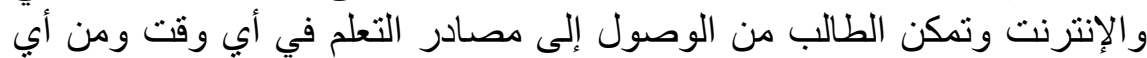
مكان.

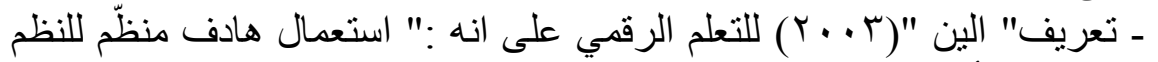
الإلكترونية أو الحاسوب في دعم عمليات التعلم"، ".كما تبينه الصورة التهان التالية:

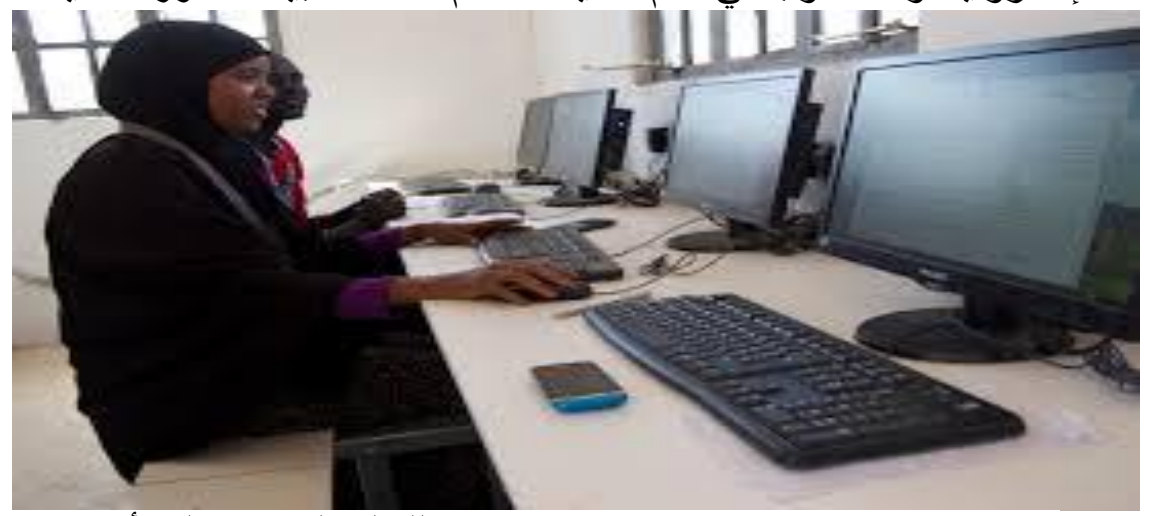

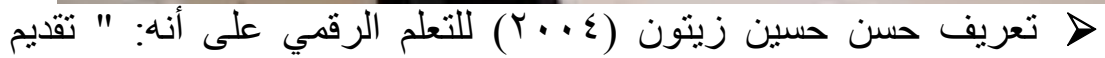

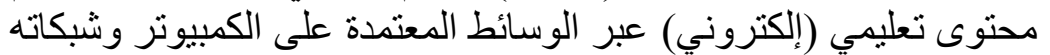

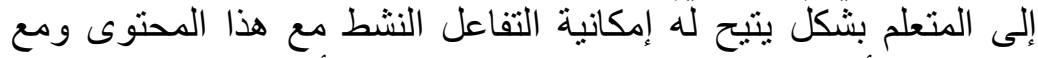

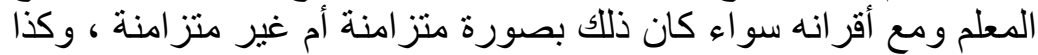

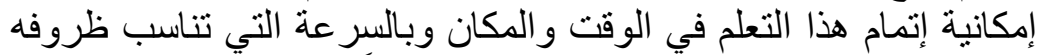

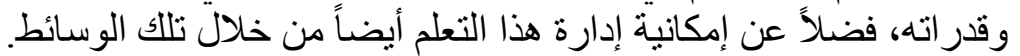
r ـ أنماط التعليم الرقمي:

التعلم الرقمي المباشر : و الذي: الذي يتمثل في تلك الأساليب و التقنيات

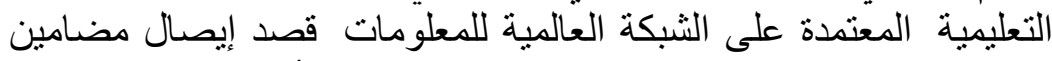

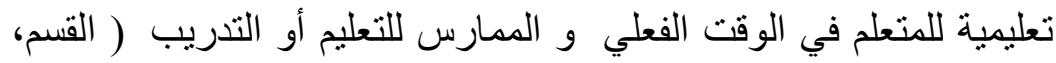

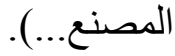
التعليم الرقمي غير المباشر: و هو الذي يتمثل في عملية التعلم من خلال

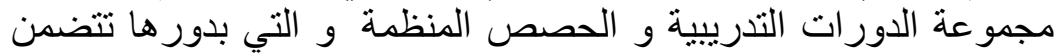

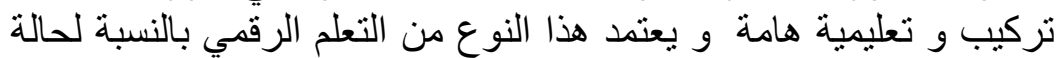

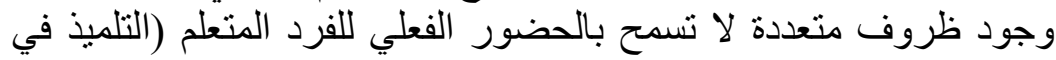
المدرسة، الجامعة، العامل في البيئة المهنية). 


\section{د/وهيية الجوزي ظليفاتي و د/سليم مغراني}

بــ المعايير المعتمدة في مجال التعليم الرقمي:

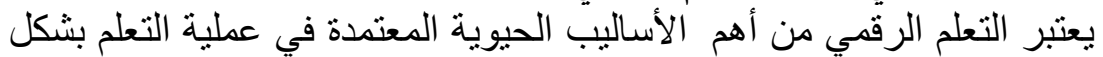

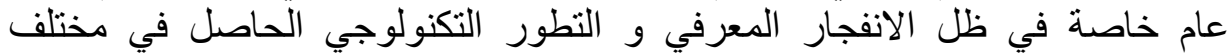

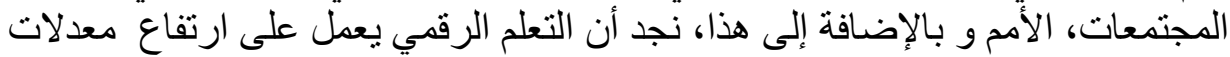

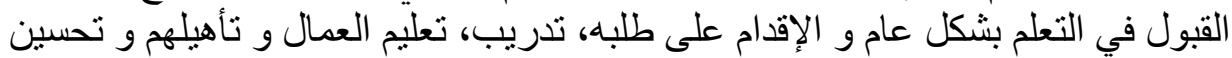

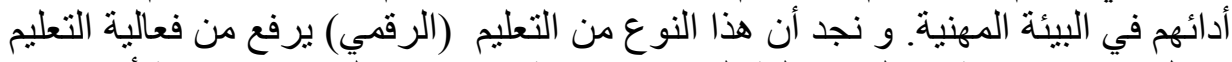

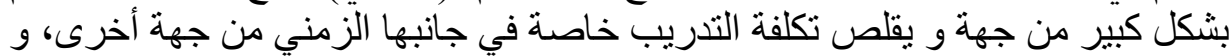

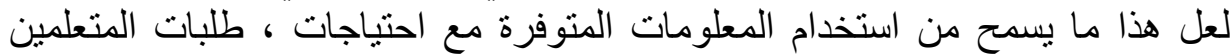

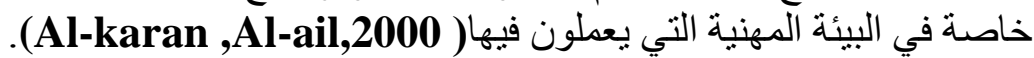

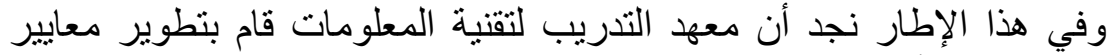

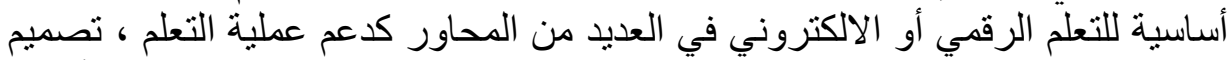

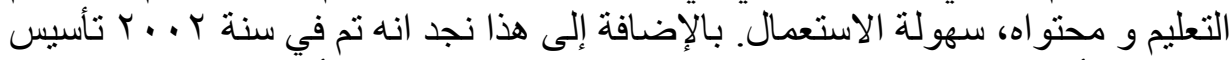

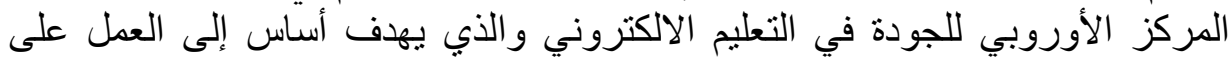

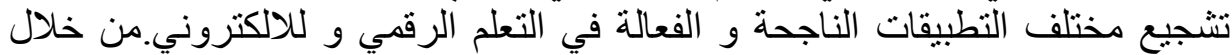

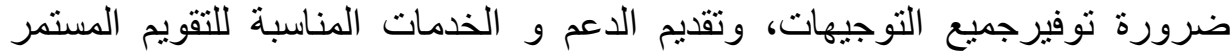

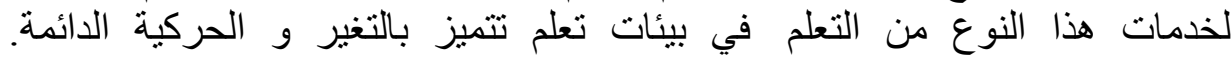

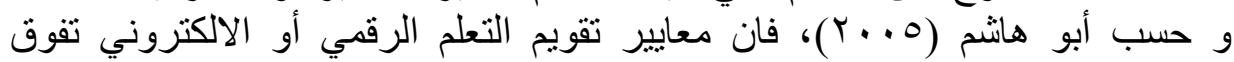

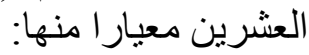
كثافة التفاعل بين المستخدم و البرنامج. كثافة التدريبات و تنوعها.

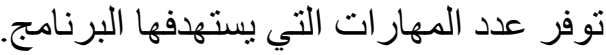

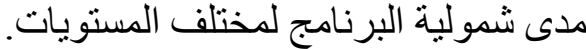

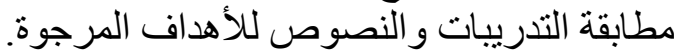

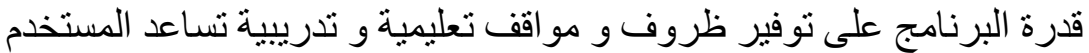
على التعلم (متعلم في البيئة الددرسية، البيئة المهنية). وقد أكدت الدراسة أن الجودة في التعلم الرقمي و الالكترة الكتروني يمكن أن نحققها من

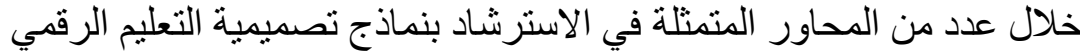

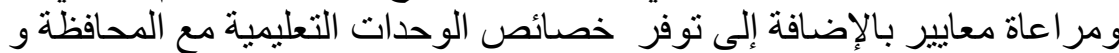

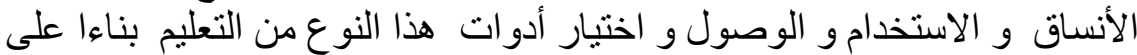

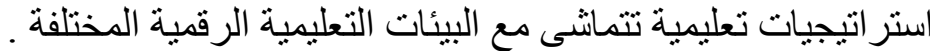

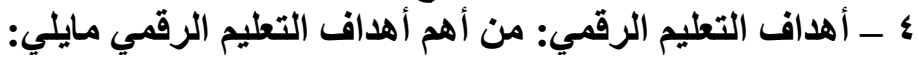
ه القدرة على تلبية حاجات و رغبات الفيات المتعلمين المعرفية و العلمية. 
• تحسين عملية الاحتفاظ بالمعلومات المكتسبة و الوصول إليها في الوقت

المناسب.

سرعة تجديد المعلومات و المعارف و ترتيبها حسب أهميتها و الموقف

المعاث.

تحسين التفاعل و التعامل بين طرفي العملية التعليمية ( المعلم و المتعلم:

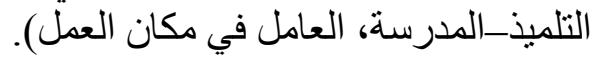

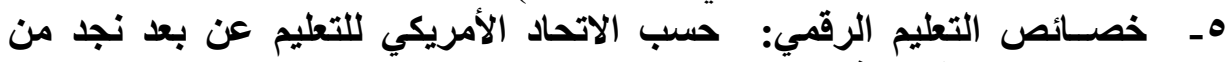
خصائص التعليم الرقمي نذكر مايلي:

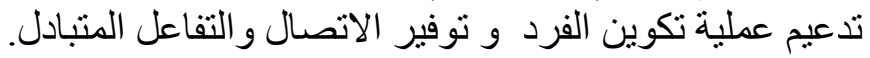

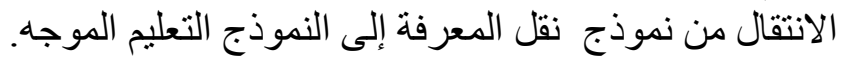

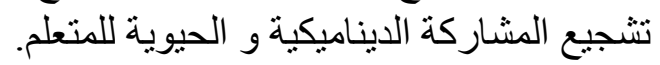

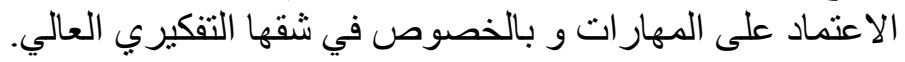

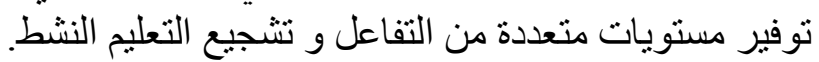

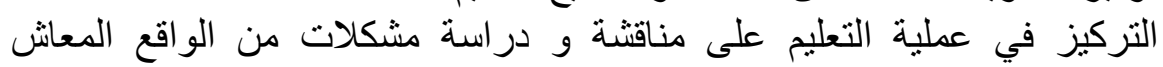

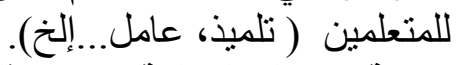

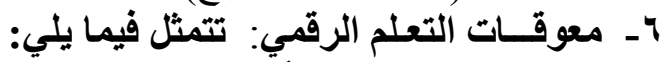

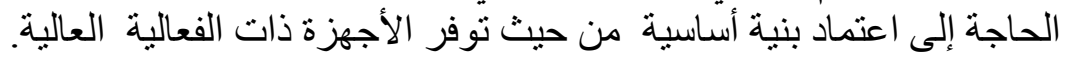

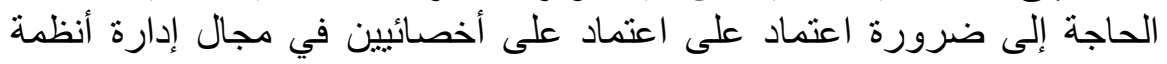
التعلم الرقمي و الالكتروني.

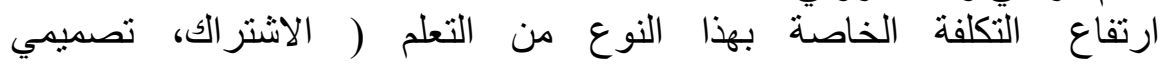

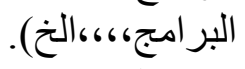
ضعف بعض المترلخعلمين و المتدربين على الاستعمال الجيد الناجح ، و السهل

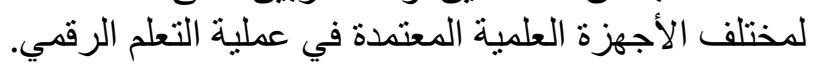

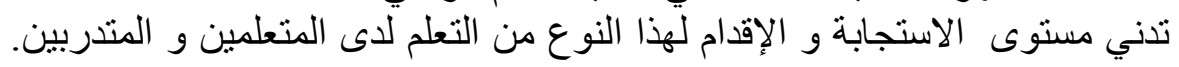

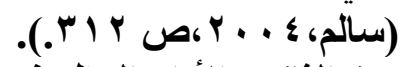

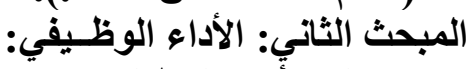

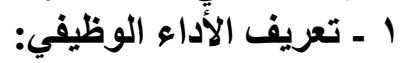

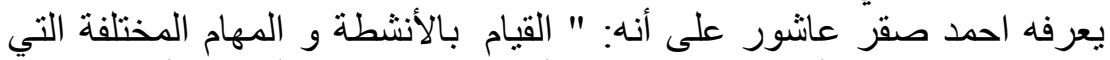

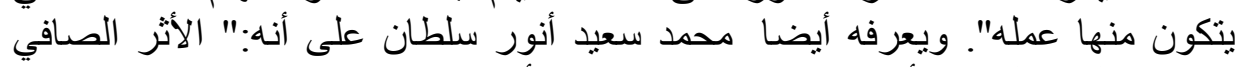

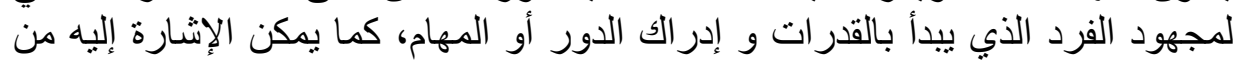

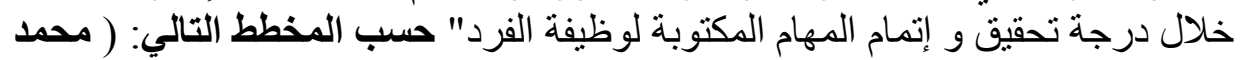

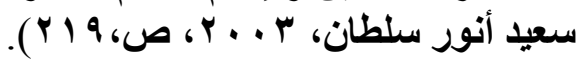




\section{د/وهيية الجوزي ظليفاتي و د/سليم مغراني}

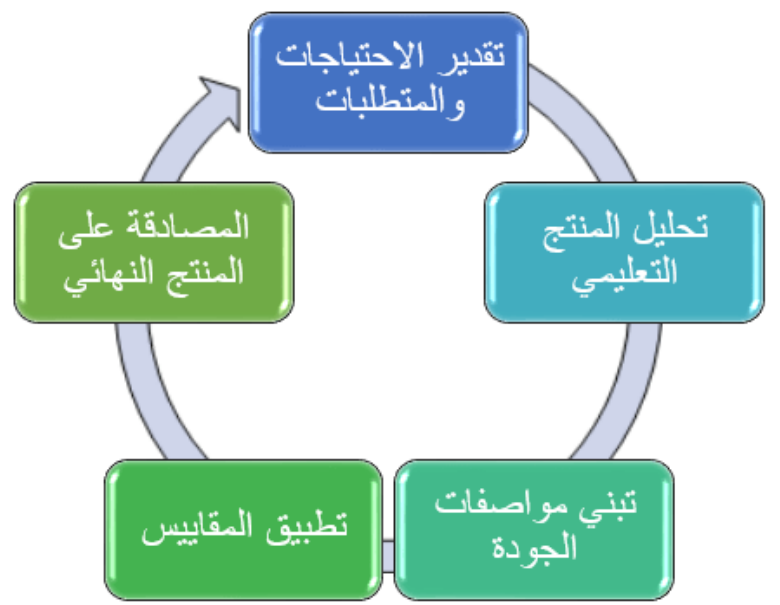

كما يعرف أيضا على أنه: " تحقيق و إتمام المهام المكونة لوظيفة الفرد و هو يعكس

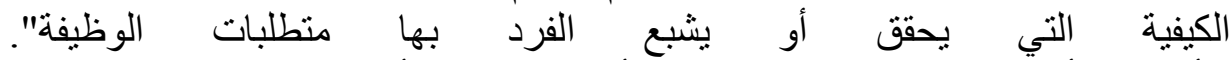
ـ أبعساد الأداء: عموما يعتمد في قياس الأداء على ثلاث أبعاد جزئية منمثلة فيما يلي:

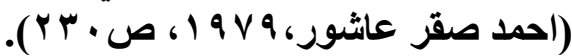
= نوعيـة الجهـة المبذول: نعني بها مستوى الدقة و الجودة و كذا درجة مطابقة

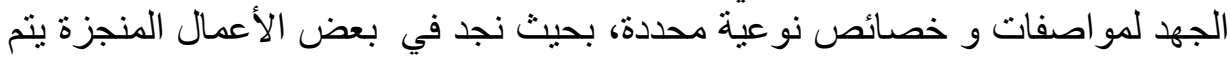

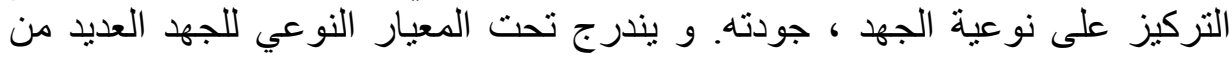

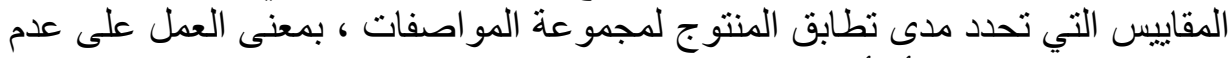

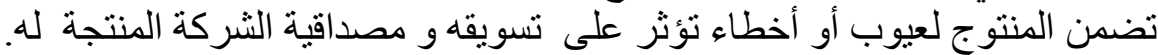

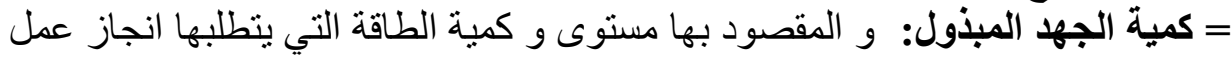

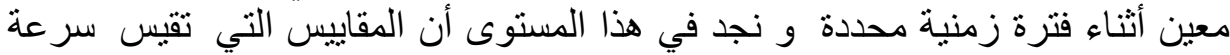

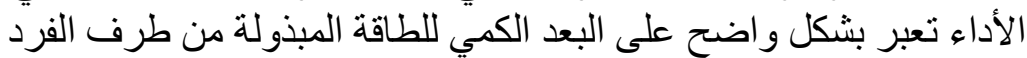

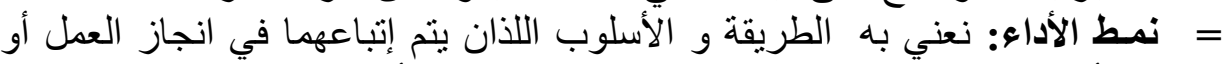

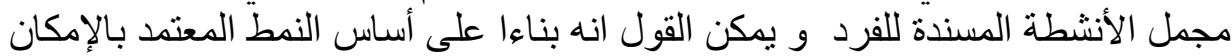

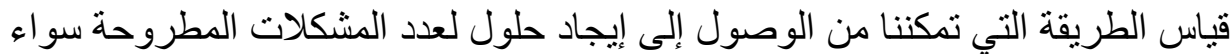

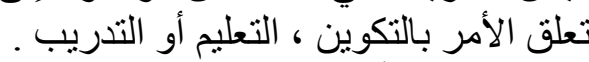

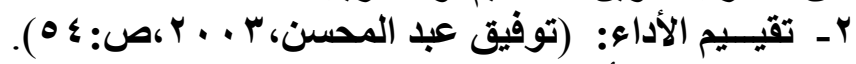

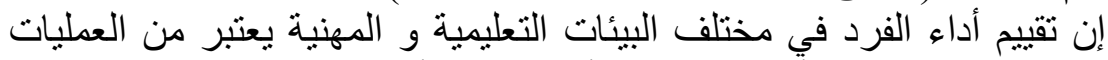

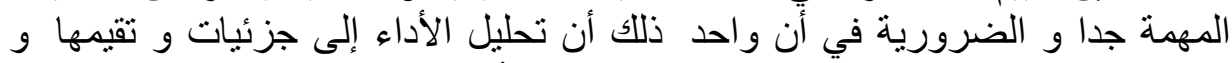
تحديد درجة الكفاءة الحالية و الدنوقعة لديه يعتبر أساسا فعالا و ترشيدا محكما لتقييم التيات 


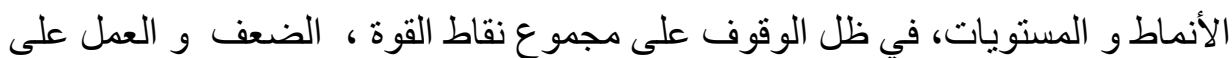

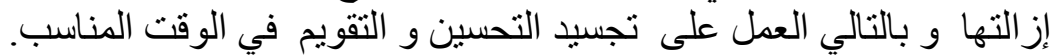
المبحث الثالث: دور التعلم الرقمي في البيئة المهنية:

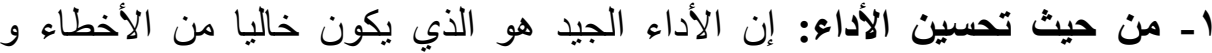

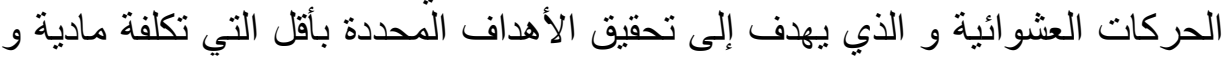

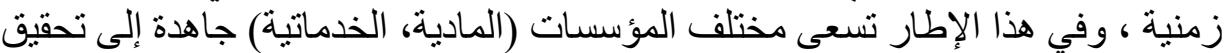

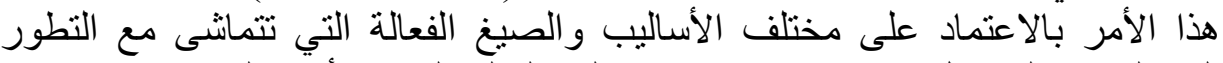

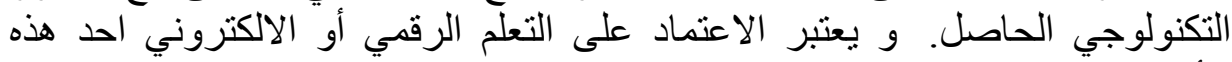

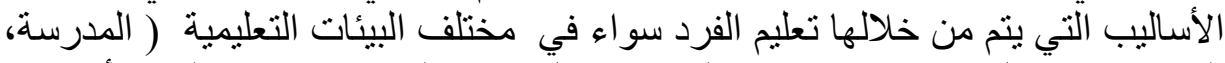

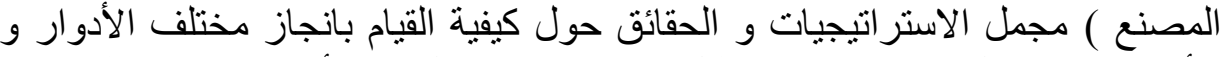

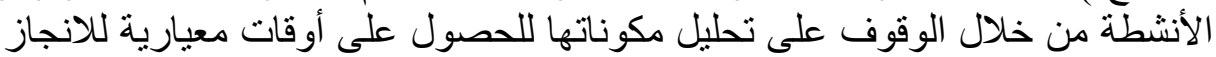

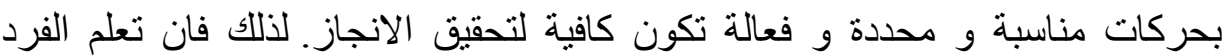

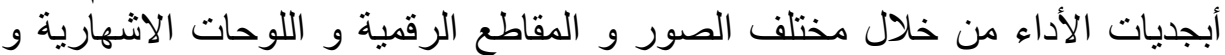

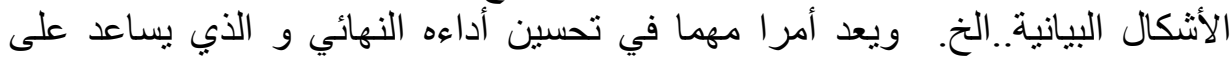
تحقيق الأهداف المسطرة له له الهن r- من حيث المحتوى والأهداف: يعمل التعلم الرقمي على جعل محتوى و مضمون

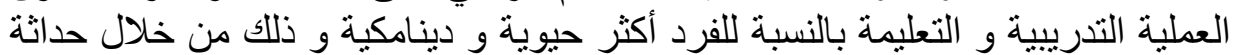

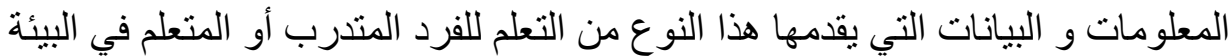

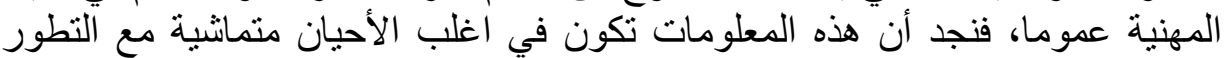

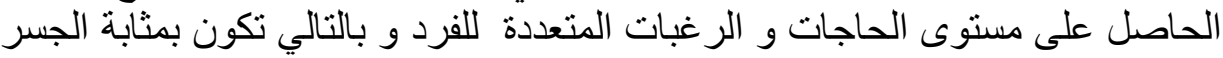

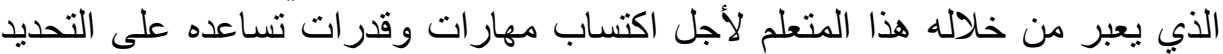

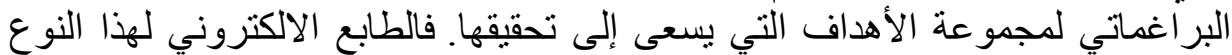

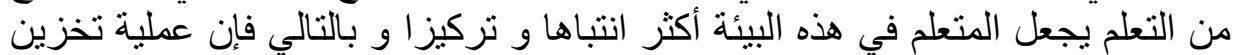

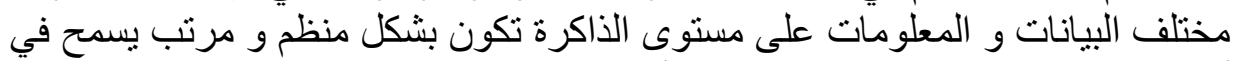

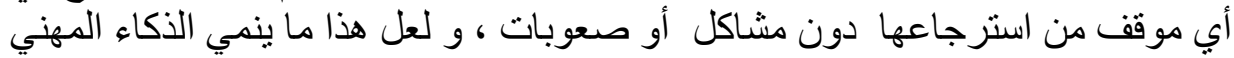

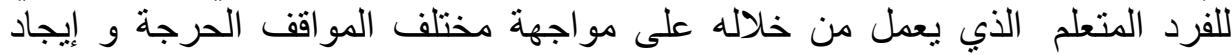

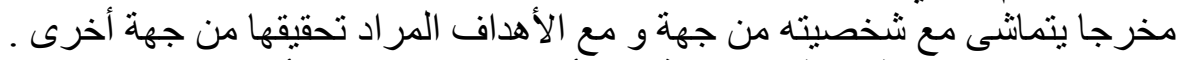

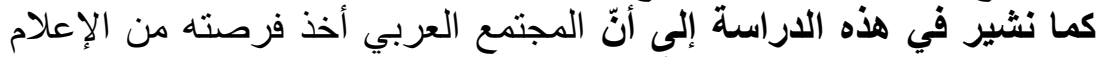

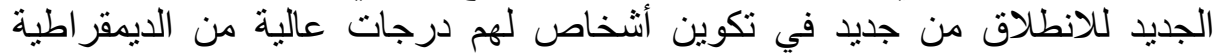

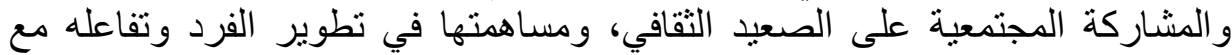

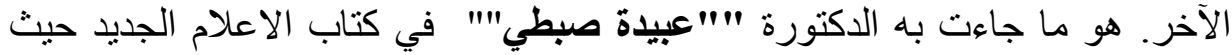

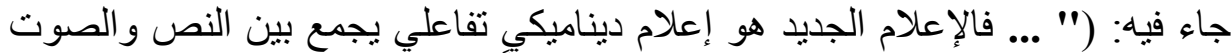
و الصورة في ملف واحد، وتقوم فيه التقنية دور ا مهماً في إضفاء التفاعلية على هذا النوع 


\section{د/وهيية الجوزي ظليفاتي و د/سليم مغراني}

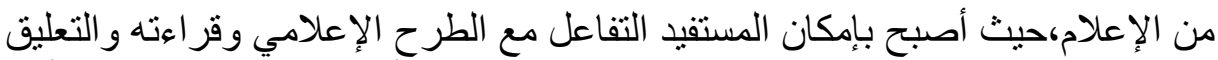

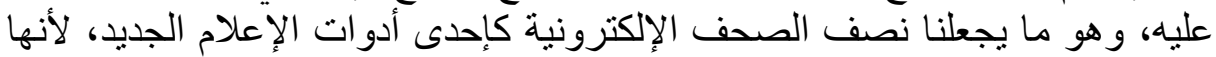

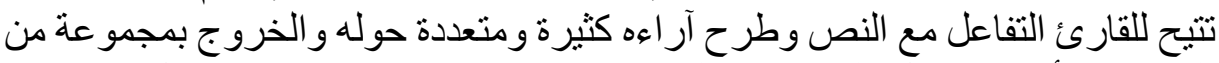

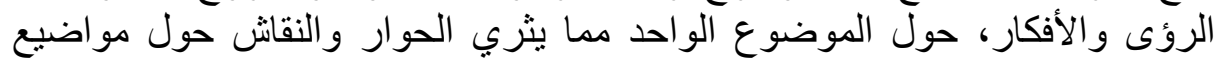

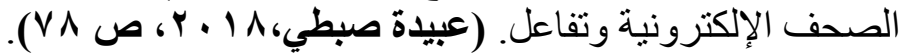

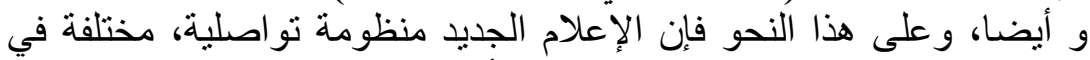

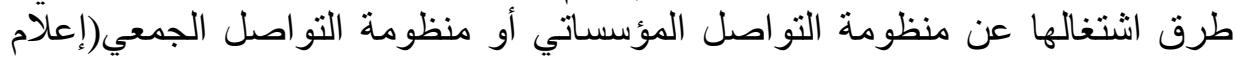

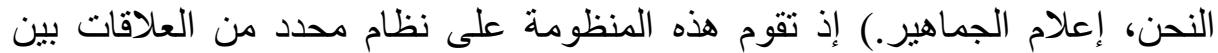

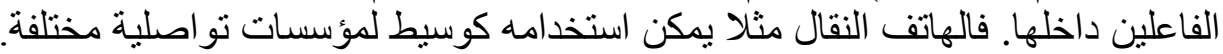

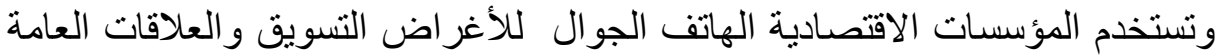

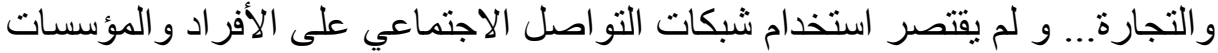

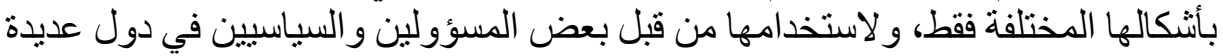

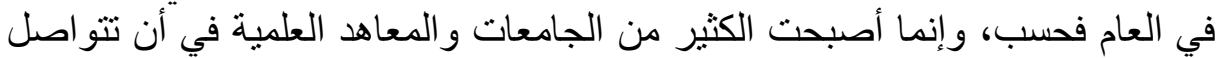

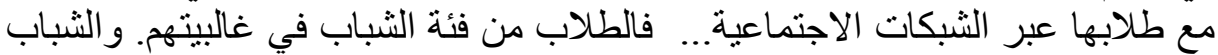

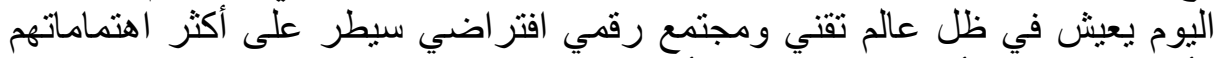

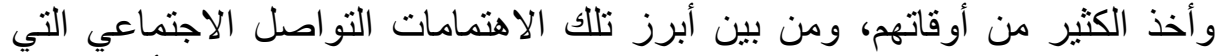

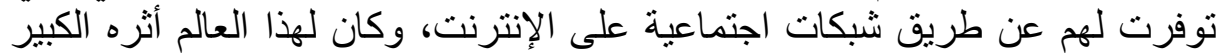

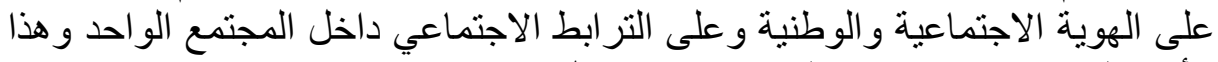

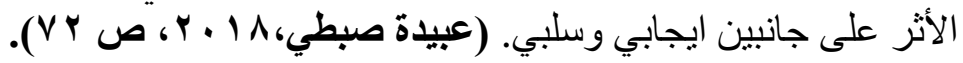
المبحث الرابع: مزايا التعليم الالكتروني وسلبياته التئه

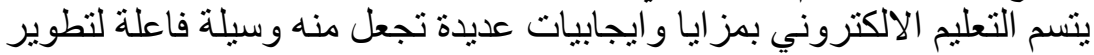

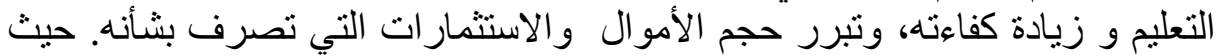

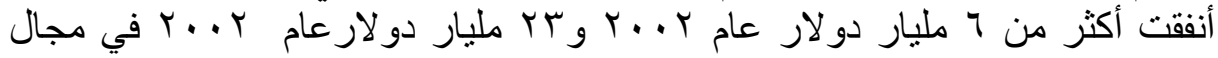

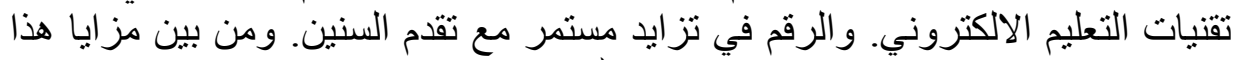

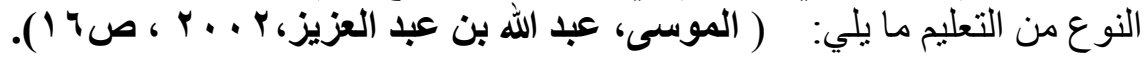

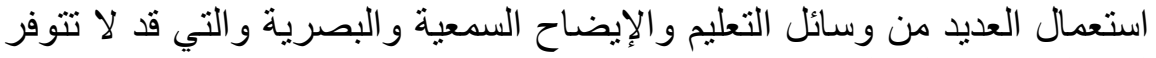
لدى العديد من المتعلمين.

جعل التعليم أكثر تشويقا ومتعة والعين الابتعاد عن الرتابة والملل في التعليم التقليدي. تعليم عدد كبير من الطلاب دون قيود الزمان ولئ والمكان المكان. اختصار الوقت وتقليل الجهد المبذول في التعليه.

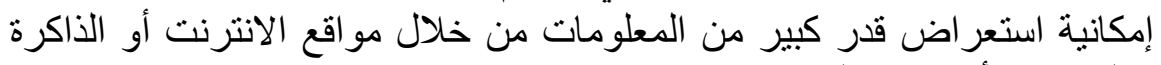

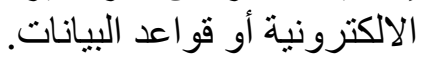
المواكبة الآنية للتطور العلمي المذهل الحاصل في كافة ميادين المعرفة. 


$$
\text { إمكانية تبادل الحوار الذي. }
$$

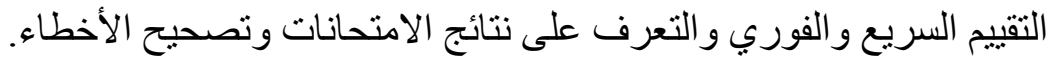

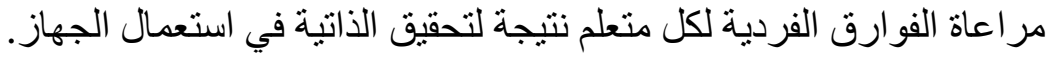

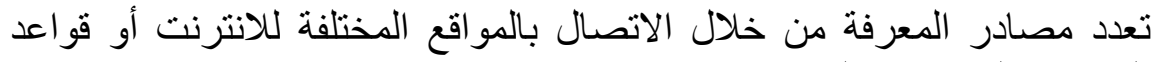
البيانات و المكتبات الالكترونية.

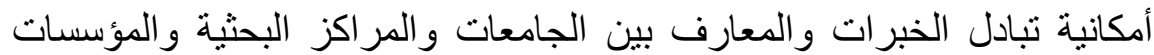

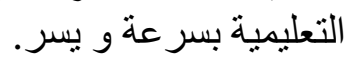

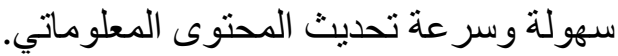

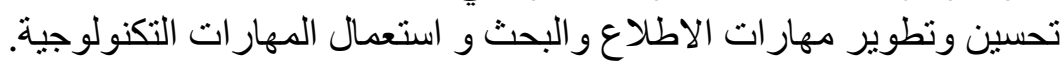

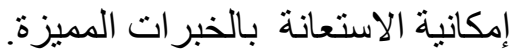

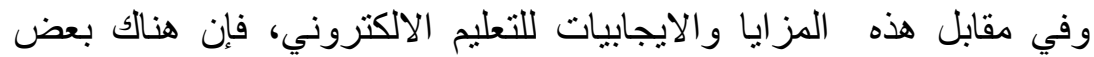

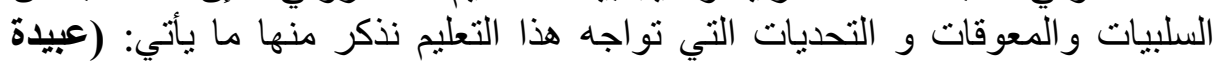

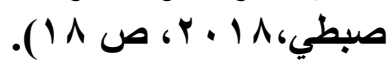
ضعف التفاعل الإنساني بين الأستاذ و الطالب.

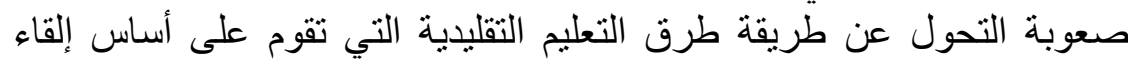

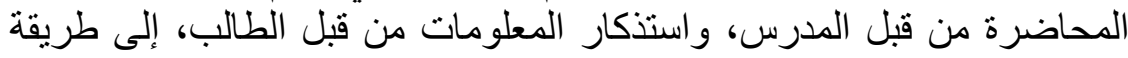

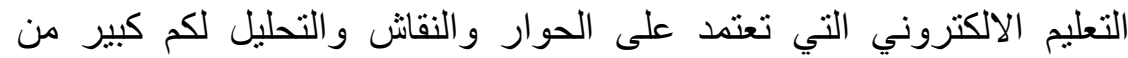

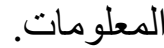
افتقار نسبة كبيرة من المدرسين والطلبة لخبرة التعامل مع وسائل تكنولوجيا

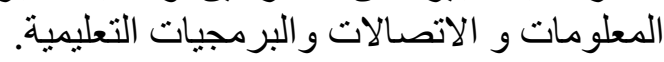

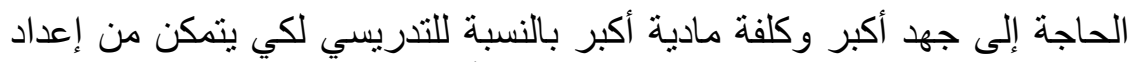

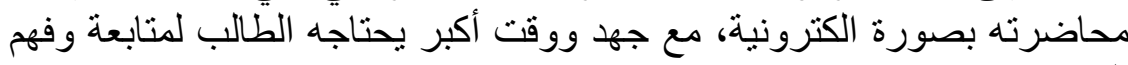

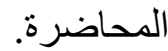
عدم توفر مستلزمات التعليم الالكتروني بشكل و اف، من أجززة حاسوب ووسائل عرض الكترونية، و الاتصال عبر شبكة الانترنت و شبكة اتبكة اتصالات بين الجامعات و المر اكز البحثية

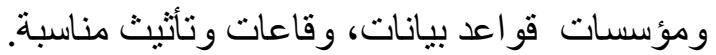

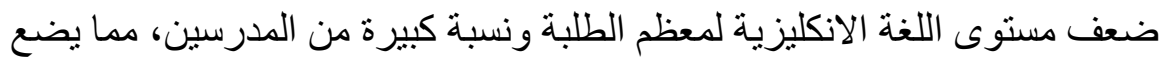

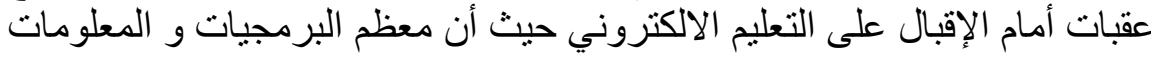
مكتوبة باللغة الانكليزية. 


\section{د/وهيية الجوزي خليفاتى و د/سليم مغراني}

الافتقار إلى التمويل الكافي مع نقص في الكو ادر الفنية المدربة على تشغيل و صيانة

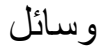
الاتصالات وتكنولوجيا المعلومات. وجود عقبات إداريه تتمثل أحيانا بقيادات جامعية غير واعية وغير واتير متحمسة

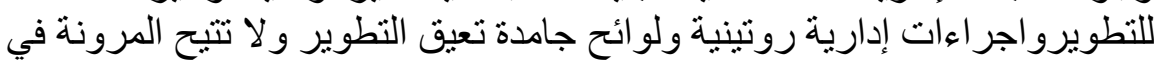

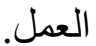

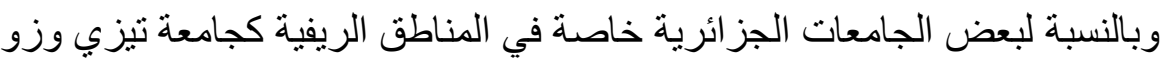

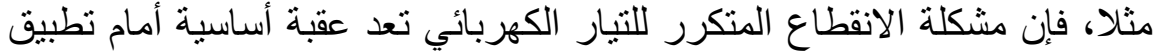

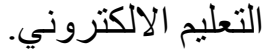
الاستنتاجات والتوصيات:

من خلال ما تقدم يمكن الخروج بات بالاستنتاجات الآتية:

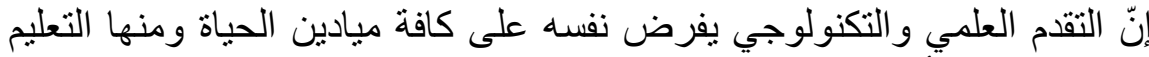

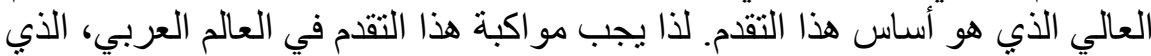

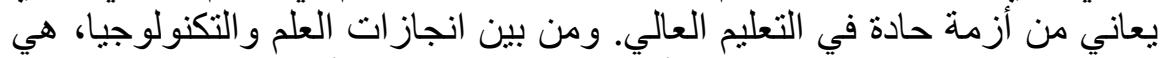

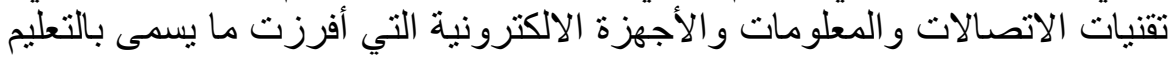

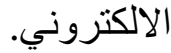

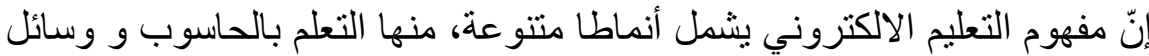

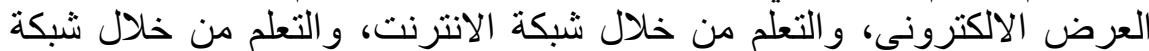

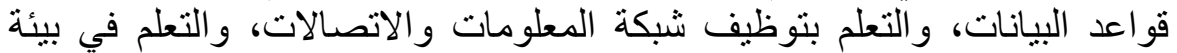
افتر اضية، وتوظيف تقنية التعلم عن بعد. أندات

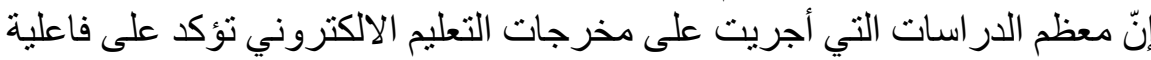

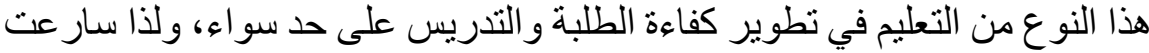

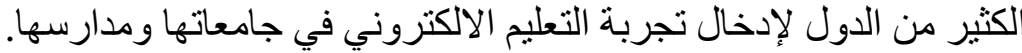

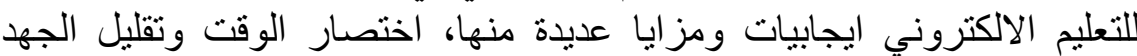

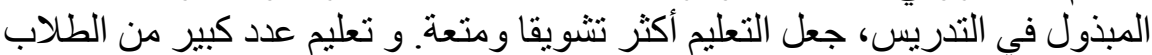

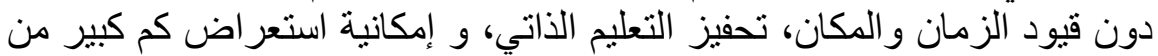

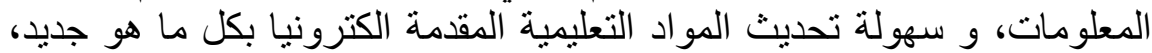

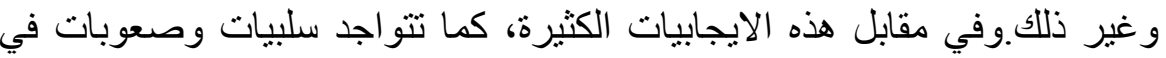

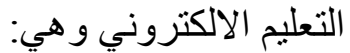
ضعف التفاعل الإنساني بين الأستاذ و الطالب.

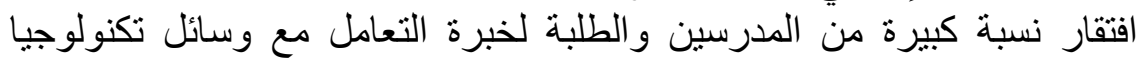

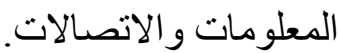


ل عدم توفر مستلزمات التعليم الالكتروني بشكل كاف، و مشكلة الانقطاعالمتكرر للتيار الكهربائي التي تعد عقبة أساسية أمام تطبيق التعليم الالكتروني فيها

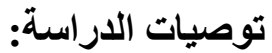

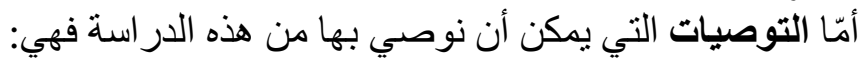

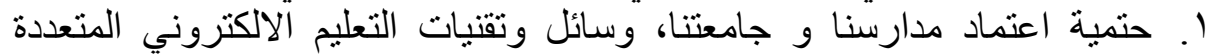

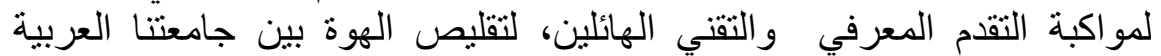
و الجامعات العالمية.

r. توفير الدعم المادي و مستلزمات وتقنيات التعليم الالكتروني من حواسيب وسائل

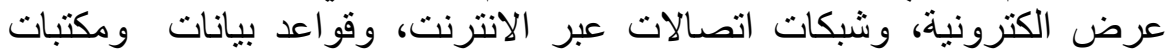

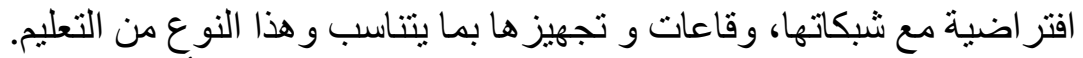

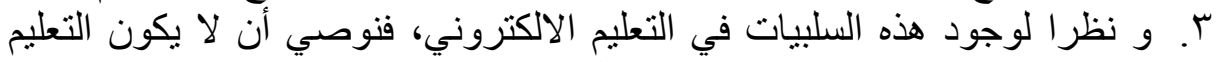

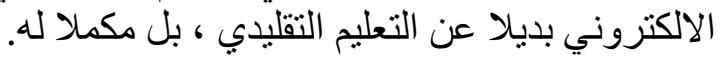

\section{خاتمــة:}

إنّ التعلّم الرقمي أو الالكتروني يعتبر أساسا، آلية فعالة في ترسيخ مختلف

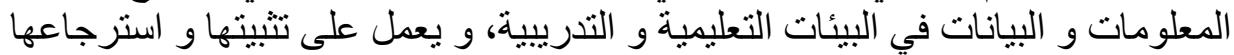

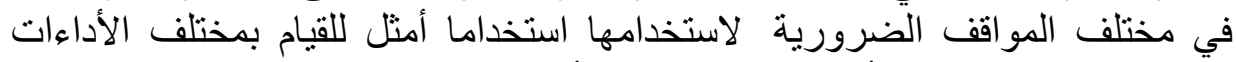

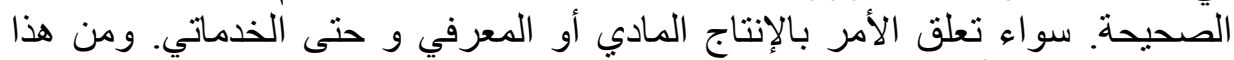

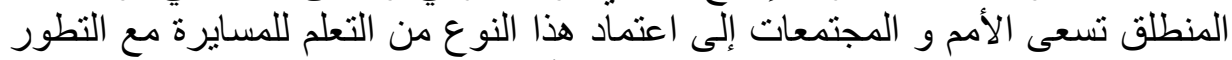

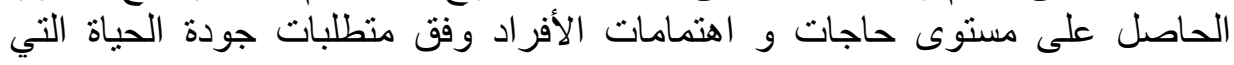
يسعون إلى تحقيقها في مجتمعاتهر. 


\section{د/وهيية الجوزي ظليفاتي و د/سليم مغراني}

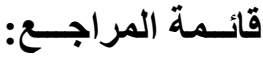

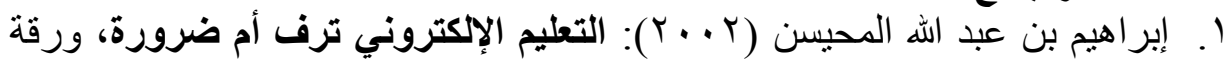
عمل مقدمة إلى ندوة: مدرسة المستقبل، جامعة الملك سعود ، المنعقدة في الفترة المبرة $1 V_{-} 17$

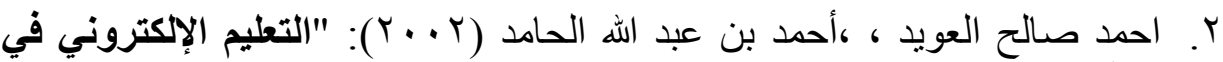

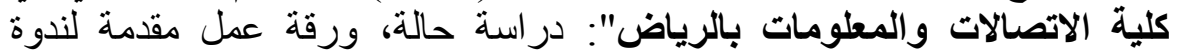

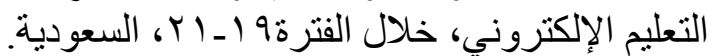

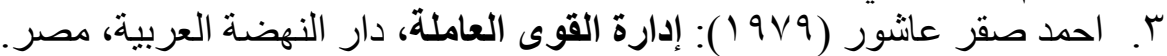

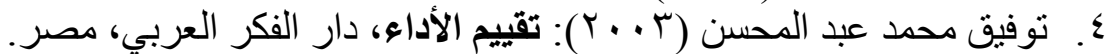

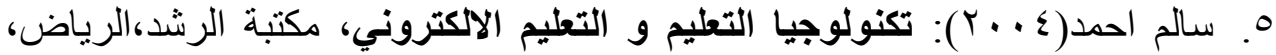
السعودية.

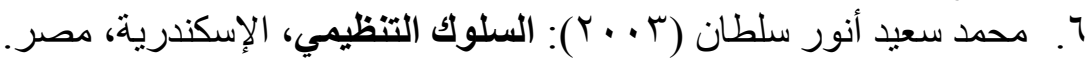

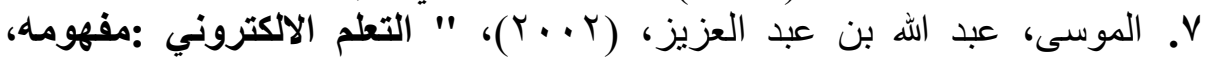

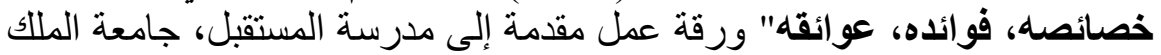

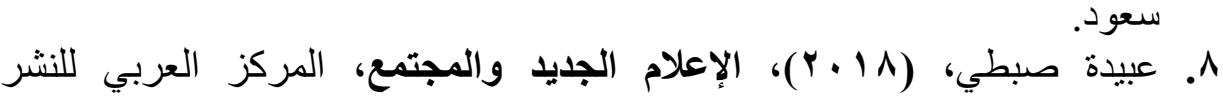
و التوزيع، مصرة.

9. 1.- Al- Karam; A. M. Al- Ali \& N. M.(2001). E- learning: the new breed of education. In Billeh, V. \& Ezzat, A.(Eds.), Education development through utilization of technology: UNESCO Regional Office for Education in the Arab States.

10. ' 1 - Sterling,J,Gray,M, (1991) " The effect of simulation software on (37) students attitudes

11. and understanding in introductory statistics " , Journal of Computer, Mathematics, and

12. Science Teaching, 10 (4), pp (51- 55).

13. ' r-Ravaglia, A. , (1995), " Computer based mathematics and physics ", (33) Gifted Child

14. Quartely, 39 (1), pp $7-13$.

15. 1 1 - Watkins, G. , (1999), " Effects of cd rom instructions on achievement and

16. Attitudes ", D. A. I. 571(4), October, 1446-A.

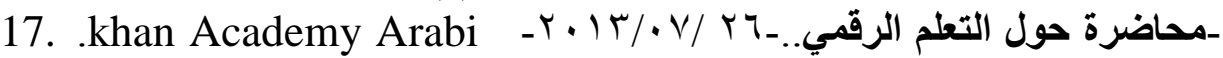
YouTube l $\varepsilon-$ 